\title{
Medievalista
}

Online

12 | 2012

Número 12

\section{Os Lóios em Portugal: origens e primórdios da Congregação dos Cónegos Seculares de São João Evangelista}

Tese de Doutoramento em História apresentada à Faculdade de Ciências Sociais e Humanas da Universidade da Universidade Nova de Lisboa, Abril 2011. Orientação do Professor Doutor José Matoso e do Professor Doutor Bernardo Vasconcelos e Sousa

Isabel Castro Pina

\section{(2) OpenEdition}

Edição electrónica

URL: http://journals.openedition.org/medievalista/715

DOI: 10.4000/medievalista.715

ISSN: 1646-740X

Editora

Instituto de Estudos Medievais - FCSH-UNL

Edição impressa

Data de publição: 1 junho 2012

\section{Refêrencia eletrónica}

Isabel Castro Pina, « Os Lóios em Portugal: origens e primórdios da Congregação dos Cónegos

Seculares de São João Evangelista », Medievalista [Online], 12 | 2012, posto online no dia 19 fevereiro 2014, consultado o 22 setembro 2020. URL : http://journals.openedition.org/medievalista/715; DOI : https://doi.org/10.4000/medievalista.715

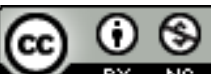

Mediavalista está licenciado com uma Licença Creative Commons - Atribuição-NãoComercial 4.0 Internacional. 
Título: Apresentação de Tese

Os Lóios em Portugal: origens e primórdios da Congregação dos Cónegos Seculares de São João Evangelista.

Tese de Doutoramento em História apresentada à Faculdade de Ciências Sociais e Humanas da Universidade da Universidade Nova de Lisboa, Abril 2011. Orientação do Professor Doutor José Matoso e do Professor Doutor Bernardo Vasconcelos e Sousa.

Autor(es): Isabel Castro Pina

Enquadramento Institucional: Instituto de Estudos Medievais FCSH - UNL

Contacto: isabelcastropina@sapo.pt

Fonte: Medievalista [Em linha]. №12, (Julho - Dezembro 2012). Dir. José Mattoso.

Lisboa: IEM.

Disponível em: http://www2.fcsh.unl.pt/iem/medievalista/

ISSN: $1646-740 \mathrm{X}$ 


\section{Apresentação de Tese}

\section{Os Lóios em Portugal: origens e primórdios da Congregação dos Cónegos Seculares de São João Evangelista.}

Tese de Doutoramento em História apresentada à Faculdade de Ciências Sociais e Humanas da Universidade da Universidade Nova de Lisboa, Abril 2011. Orientação do Professor Doutor José Matoso e do Professor Doutor Bernardo Vasconcelos e Sousa.

\section{Isabel Castro Pina}

No panorama da investigação histórica medieval portuguesa dos últimos anos, as temáticas de história religiosa são uma constante e têm sido alvo de diferentes análises. Se até há pouco tempo os estudos de conjunto ao nível das ordens e movimentos religiosos não eram frequentes, actualmente têm vindo a multiplicar-se as abordagens globalizantes que se interessam também pela composição social das comunidades e pelas formas de vivência religiosa dos seus membros.

A dissertação que aqui se apresenta - Os Lóios em Portugal: origens e primórdios da Congregação dos Cónegos Seculares de São João Evangelista - insere-se nesta linha de investigação. Com este trabalho procurou-se caracterizar a especificidade da congregação dos lóios, evidenciando os seus aspectos institucionais e religiosos, e compreender as razões que contribuíram para que estes cónegos se implantassem tão rápida e incisivamente no território nacional e assumissem um papel relevante na vida cultural, religiosa e política de Portugal nos finais da Idade Média.

A Congregação dos Lóios foi até agora pouco estudada, não obstante a sua especificidade institucional, o prestígio intelectual dos seus membros e o entusiasmo que suscitou em meios próximos da corte bem como o seu carácter eminentemente nacional. 
A inexistência destes estudos não se deve à ausência de fontes documentais. De facto, a documentação conservada não é abundante mas permitiu estabelecer um corpus documental que engloba a documentação produzida no âmbito da congregação ou a ela dirigida pelas autoridades eclesiásticas e civis. Este acervo encontra-se quase exclusivamente no Arquivo Nacional da Torre do Tombo, nos arquivos distritais de Braga, do Porto e na Biblioteca Pública de Évora. Como é habitual nos arquivos de instituições religiosas, a documentação divide-se em duas grandes secções, uma directamente relacionada com a administração do património e a outra que diz respeito à história interna e ao governo da ordem e das comunidades conventuais que inclui crónicas e registos históricos; regras e constituições; actas capitulares e de visitações; livros de profissões e óbitos; listas de membros e compromissos das confrarias anexas; costumeiros, etc. Os documentos deste segundo grupo foram os que mais informações aportaram para este estudo, destacando-se, pela sua singularidade, o Memorial do Novo Estado Apostólico, crónica da congregação da autoria de Paulo de Portalegre, datada de 1468, e os livros das actas dos capítulos gerais dos lóios realizados entre 1480 e 1500. $\mathrm{Na}$ análise das fontes é igualmente importante considerar o material que desapareceu e aquele que "nunca existiu", isto é, que nunca chegou a ser posto por escrito. No caso dos lóios, as lacunas verificaram-se sobretudo no campo das práticas religiosas e vida interna da congregação. Faltam actas de visitações anteriores ao século XVI, livros de profissão, documentação sobre estudos e planos de formação dos cónegos, inventários das livrarias, homiliários, etc.

O século XV português foi um século de charneira e de intensas transformações sociais, marcado por uma profunda crise política, económica e demográfica originada no século anterior mas que se prolongou de forma acentuada pelo menos durante a primeira metade da centúria de quatrocentos. A ascensão da nova dinastia e as vitórias contra o reino de Castela, a conquista de Ceuta e o êxito das primeiras viagens africanas contrastaram com outras realidades menos positivas e gloriosas que também fizeram parte do quadro nacional. Houve peste e fome, em vagas sucessivas, que atravessaram todo o século, dizimando a população ainda mal refeita da grande hecatombe de 1348. Houve maus anos agrícolas e houve guerras e conflitos armados, em território português, em Castela e em África, que consumiram vidas humanas e absorveram muitos recursos. Apesar de tudo, a estabilização política do reino foi estimulando, ainda 
que lentamente, a reconstrução económica e social. As cortes reuniram-se com frequência procurando consolidar o equilíbrio das forças sociais e dar resposta aos novos desafios que se apresentavam. Do ponto de vista cultural, as mudanças parecem ter sido mais rápidas e é conhecida a acção dinamizadora da dinastia de Avis no que diz respeito à actividade literária e à criação artística e às relações estabelecidas com outras cortes da Europa. Assistiu-se ao desenvolvimento de uma importante cultura laica, polarizada em torno da corte régia que, sem excluir outras tradições, se manifestou por exemplo no crescimento das livrarias régias e principescas e na produção de obras originais e incremento de traduções.

Não é possível ignorar este contexto quando se pretende compreender as coordenadas que marcaram o horizonte espiritual do século XV. Nesta época, o fenómeno da religiosidade revela-se de singular importância para a compreensão da cultura portuguesa, seja pela sua influência nos conceitos, valores e modelos, seja pela sua relação com a distribuição dos poderes políticos, económicos e sociais. O aparecimento de novas ordens religiosas e a multiplicação das devoções são dois aspectos marcantes nesta época cujos contornos e implicações não foram ainda suficientemente esclarecidos. Em Portugal como em toda a Europa Ocidental, o ambiente geral foi de religiosidade particularmente activa. O cisma e a crise institucional da Igreja, os abusos do clero, o desregramento da vida monástica, a acumulação de benefícios e o flagelo dos abades comendatários, entre os aspectos negativos, não devem ocultar os sinais igualmente evidentes de que existiam outros sectores do clero que lutavam pela renovação da Igreja, pela reforma dos costumes e pelo aprofundamento intelectual. Parece ter sido precisamente a crise da Igreja e a necessidade premente de reforma que aceleraram a renovação da espiritualidade e contribuíram para que em algumas ordens religiosas se registassem tentativas de regeneração e mudança anteriores ao Concílio de Trento, verificando-se ao mesmo tempo a revalorização do papel dos leigos dentro da Igreja.

Em Portugal, de modo particular, este ambiente de renovação religiosa foi precedido e acompanhado pelo intenso movimento de fundações observantes iniciado nos finais do século XIV. Nunca é demais sublinhar a importância do contributo que a corrente observante dos mendicantes provocou no ambiente religioso português, ajudando a combater o relaxamento na vida regular, avivando as consciências e apelando a uma 
vivência do cristianismo mais pessoal e autêntica. Entre nós, o interesse pela reforma eclesiástica associou-se também à valorização da cultura humanista e amante das letras, e as figuras preeminentes da reforma coincidiram com as que se destacaram no cultivo das letras e na difusão de novas formas de espiritualidade, tanto no âmbito da corte régia, como das universidades estrangeiras, cúria romana, etc.

Foi neste contexto que surgiu a congregação dos Lóios, concretizando o ideal recorrente de reforma que imperava em toda a Cristandade. O fundador João Vicente propunha-se renovar o estado clerical, retomando os usos antigos e o modelo da Igreja primitiva, segundo o ideal de vida apostólica. A eficácia do seu testemunho vinha de corresponder à mentalidade, aos gostos, às concepções e às necessidades da época. A sua especificidade estava na conjugação de uma disciplina conventual exigente, com a devoção de tipo emocional (muito própria da época, mas sem cair no dolorismo que é a deturpação do mesmo gosto), o apreço pela formação intelectual, a capacidade prática de envolvimento de uma clientela exigente por diversos meios, nomeadamente a música sacra e o cuidado das cerimónias litúrgicas, e a actividade pastoral.

Os valores propostos eram os próprios da época, permeados pelo humanismo cristão, de origem italiana, e pela devotio moderna, de pendor flamengo ou renano. Os autores e as leituras que alimentaram a espiritualidade dos lóios e as práticas religiosas vividas nas suas casas e propagadas junto daqueles que recebiam a sua orientação, reflectiam claramente estas influências.

A congregação dos Lóios foi de facto um produto da reforma. As suas origens em ambiente urbano, culto e próximo da corte, e o percurso seguido nos primeiros anos pequenos grupos de oração integrando clérigos e leigos, depois vida religiosa em comunidade, exigente e disciplinada - apontam para um ideal reformador. A congregação beneficiou do impulso da observância mendicante e das medidas reformadoras de origem diocesana e também da proximidade e dos apoios recebidos da corte. Participou do movimento intelectual que reabilitou os estudos teológicos e a espiritualidade "moderna".

O perfil institucional da congregação foi determinado pela influência italiana da congregação congénere de S. Jorge de Alga em Veneza, na normativa teórico-prática 
que caracterizava o governo e a organização interna dos lóios, as relações entre as casas, a sua hierarquia no conjunto da ordem, bem como a constituição da comunidade. Do ponto de vista jurídico, utilizaram uma nova forma institucional, a congregatio, que foi a primeira instituição do género a ser aprovada entre nós, sem votos solenes, à semelhança da congregação italiana, com um regime de governo centralizado, que harmonizava a autoridade do capítulo com a do reitor-geral. Contudo, a ideia de participação do poder que, nas novas ordens religiosas se aplicava à autoridade do capítulo e à rotação dos cargos, teve, entre os lóios, um horizonte limitado, na medida em que os elementos que incorporavam o capítulo e os que ocupavam os demais cargos de governo eram quase sempre os mesmos.

A sua espiritualidade inspirou-se nas formas tradicionais de espiritualidade monástica oração do ofício divino, prática do silêncio e da clausura, lectio divina - que adaptaram com êxito às tendências fundamentais da observância e das correntes de religiosidade da Baixa Idade Média. A congregação contribuiu, de algum modo, para que o património ideal da Idade Média monástica não se perdesse, transmitindo-o, renovado, às gerações seguintes. A revitalização dessa espiritualidade passou pela incorporação de elementos peculiares das novas tendências religiosas, em especial da devotio moderna. Os principais componentes deste fenómeno espiritual - humanismo nobre e religioso, mística atraente e devoção afectiva visando a interioridade na relação com o divino -, encontraram lugar na espiritualidade dos lóios. A sua proximidade aos meios e autores humanistas italianos como o Abade Gomes de Florença, Luís Barbo e Lourenço Justiniano, e às respectivas congregações de Santa Justina de Pádua e de S. Jorge de Alga, o uso frequente de obras de espiritualidade que privilegiavam esta orientação devota, a recomendação de prática individuais de oração e leitura meditada ao mesmo tempo que se cultivava com esmero práticas tradicionais da espiritualidade monástica mostram como se efectuou com bons resultados o cruzamento entre as duas correntes.

No percurso dos lóios houve também momentos de dificuldade e de tensão. A principal oposição veio do poderoso arcebispo de Braga, D. Fernando da Guerra, também ele defensor da reforma, mas de uma reforma que, nos desígnios do arcebispo, se revestia de um carácter mais administrativo e institucional que privilegiava a defesa dos direitos eclesiásticos e a reorganização económica da diocese, reforçando o poder episcopal e que colidia, por isso com os interesses da congregação, sobretudo pelo privilégio de 
isenção canónica recebido da cúria romana. Estas adversidades não impediram que a congregação se desenvolvesse a um ritmo continuado. A primeira comunidade instalouse em Vilar de Frades na Diocese de Braga no ano de 1425; até ao final do século fundaram mais cinco casas, em Lamego, Lisboa, Évora e Porto e recrutaram dezenas de cónegos, numa época em que a vida religiosa regular, já o dissemos, parecia em regressão.

Considerados tradicionalmente como baluartes da reforma da Igreja no século $\mathrm{XV}$, os lóios colaboraram de forma activa nos empreendimentos de renovação eclesiástica levados a cabo pela monarquia de Avis e pela hierarquia da Igreja. João Vicente participou nas tentativas de reforma geral do clero português promovidas pelo rei $\mathrm{D}$. Duarte em 1435 e que envolveram também o abade D. Gomes de Florença. O empreendimento fracassou, mas João Vicente continuou associado a iniciativas reformistas. O infante D. Henrique encomendou-lhe a reforma dos estatutos da Ordem de Cristo. Entre outros aspectos dos novos estatutos, destaca-se a intensificação das recomendações ascéticas e a introdução de algumas práticas religiosas que não estavam consignadas nos estatutos anteriores, como a oração, o jejum, a abstinência, o silêncio, etc. Nestas recomendações reconhecem-se, sem dificuldade, algumas das práticas aconselhadas pela observância que se referiam sobretudo à vida religiosa e à disciplina interna e que podiam ser adoptadas por qualquer ordem ou instituição eclesiástica. Posteriormente, os cónegos lóios receberam outras missões régias ou pontifícias, em que se adivinham intenções reformadoras ou, pelo menos, a garantia de que essas tarefas seriam desempenhadas diligentemente. Colaboraram também na assistência hospitalar e na actividade missionária.

Os lóios contribuíram ainda para elevar o nível moral e espiritual do clero e do laicado pela pregação e, sobretudo, pela austeridade do seu estilo de vida e pela actuação de alguns cónegos em pontos nevrálgicos da vivência religiosa, sendo confessores da casa real e de algumas famílias da nobreza, mantendo um teor exigente na vida conventual, no estudo e na preparação dos seus membros, cultivando o rigor da liturgia, difundindo novas práticas devocionais, etc.

Contrastam as prescrições sinodais diocesanas recomendando repetidamente aos clérigos a frequência dos sacramentos ou o estudo da doutrina, com as recomendações 
estatutárias e práticas vividas nas casas dos lóios sobre o estudo das matérias sagradas, a oração diária do ofício divino, a participação nos sacramentos, o decoro no trajar, a reserva da clausura, etc.

Permanências medievais lado a lado com a emergência de novas sensibilidades religiosas: a congregação de S. João Evangelista oscilou entre os moldes tradicionais e a inovação. Pretendeu reformar, repondo a forma e o rigor na vida religiosa e retomando as seculares tradições monásticas, cuja exigência se atenuara com o passar dos tempos. Recuperou a ascese habitual dos meios monásticos, em especial a Liturgia das Horas, sem aligeirar nem introduzir novos costumes. A novidade da sua espiritualidade esteve mais na conjugação e interiorização de tradições diferentes do que na originalidade das suas práticas.

Os lóios contribuíram para resolver, em áreas limitadas é certo, problemas da época, nomeadamente a recuperação da disciplina comunitária dos religiosos, quer restaurando práticas e ideais antigos quer inventando ou adaptando práticas novas ou pouco difundidas, e reforçando a importância da preparação intelectual. Se não alcançaram maior influência na Igreja do seu tempo foi porque lhes faltou um apoio institucional que teria de incluir a cúria romana e todo o aparelho diocesano. O sistema das dispensas e de distribuição de benefícios criou um núcleo de autoridades eclesiásticas que dominava todas as decisões e a selecção de candidatos aos postos de autoridade cuja coesão e reprodução foi impossível romper até ao concílio de Trento.

Sem querer reduzir a história religiosa à história eclesiástica ou institucional, parecenos, que o período conturbado da reforma religiosa e das transformações profundas verificadas nos séculos XIV e XV, não se pode entender sem o estudo das ordens e congregações que, como os lóios, surgiram nesta época de mudança. A Congregação de cónegos seculares de S. João Evangelista foi, também ela, uma ordem de transição, nascida no espírito da reforma, que deu resposta às inquietações religiosas do seu tempo. 


\section{COMO CITAR ESTE ARTIGO}

\section{Referência electrónica:}

PINA, Isabel Castro - Os Lóios em Portugal: origens e primórdios da Congregação dos Cónegos Seculares de São João Evangelista. Tese de Doutoramento em História, apresentada à Faculdade de Ciências Sociais e Humanas da Universidade Nova de Lisboa, 2011. Medievalista [Em linha]. №12, (Julho - Dezembro 2012). [Consultado dd.mm.aaaa]. Disponível em

http://www2.fcsh.unl.pt/iem/medievalista/MEDIEVALISTA12 \pina1210.html. ISSN 1646-740X.

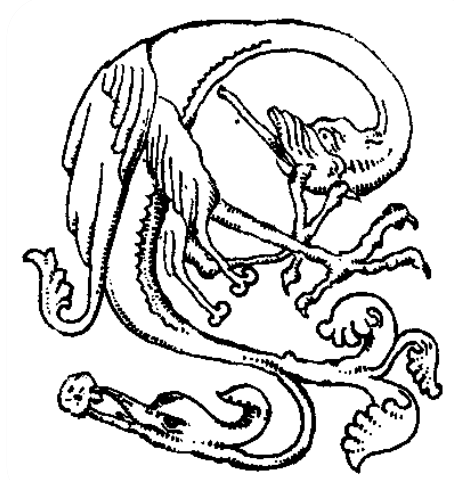

Medievalista online $N^{0} 12$ | Julho - Dezembro $2012 \odot$ IEM - Instituto de Estudos Medievais 9 www2.fcsh.unl.pt/iem/medievalista 